\title{
Perception of Partner Abuse and Its Impact on Marital Violence from Both Spouses
}

\author{
Claude Bélanger ${ }^{1,2}$, Cynthia Mathieu ${ }^{1}$, Hélène Brisebois ${ }^{1}$ \\ ${ }^{1}$ Department of Psychology, University of Quebec in Montréal, Montreal, Canada \\ ${ }^{2}$ Department of Psychiatry, McGill University, Montreal, Canada \\ Email: belanger.claude@uqam.ca
}

Received August 27 $7^{\text {th }}, 2013$; revised September 28 ${ }^{\text {th }}, 2013$; accepted October $27^{\text {th }}, 2013$

\begin{abstract}
Copyright $@ 2013$ Claude Bélanger et al. This is an open access article distributed under the Creative Commons Attribution License, which permits unrestricted use, distribution, and reproduction in any medium, provided the original work is properly cited.
\end{abstract}

\begin{abstract}
Few studies have investigated bi-directional models of marital violence. Research suggests that female victims are also often perpetrators of violence. Accordingly, some researchers propose that we should test the hypothesis that the victim and perpetrator roles can be played by both men and women. The current study addresses this issue by attempting to understand the effect that perceptions of spousal violence will have on both partners' level of marital violence. Our objectives were to verify the links between levels of violence and perceptions of violence by both partners, and actual self-reports of each type of violence perpetrated. We verified if self-reports and partner's reports of violence would differ, if one partner's abuses would influence the other partner's abuses, and whether the spouse's self-reported violence or the other spouse's perception of that violence had a differential impact on the level of violence perpetrated. Twenty-three couples in which the male partner was undergoing treatment for marital violence took part in the study. Results indicate that for both partners perceptions of partner violence modulate the level of marital violence that is perpetrated. The link between perceptions and violent behaviors appears to explain female marital violence better than that it does for males. Implications based on these results are discussed.
\end{abstract}

Keywords: Marital Violence; Psychological Violence; Physical Violence; Spousal Abuse; Perception of Abuse

\section{Introduction}

Domestic violence has been a growing concern for researchers and clinicians since more than 50 years. This important societal problem has been recognized by the American Psychiatric Association planning and research committees who is considering inclusion of a Marital Abuse Disorder diagnosis (Marital Conflict Disorder with Violence) in the new Relational disorders of the forthcoming DSM-5 (2013). Numerous studies have looked at different predictors and models that would explain and predict marital violence. A significant amount of research that has been published on marital violence is studying male perpetrators and female victims (McQueen, 2013). This might be explained by the fact that females are more likely to report spousal abuse than men, with the consequence that female violence might be underreported by men. Some authors would take a different position and support a bi-directional model of marital violence, and a growing number of studies have gone beyond the traditional model, with results indicating that spousal abuse is also perpetrated by women Some researchers concluded that a significant proportion of females seeking help for victimisation are also perpetrators of intimate partner violence (Williams, Ghandour, \& Kub, 2008). In their review article on domestic violence, McNeely and Mann (1990) state that "classifying spousal violence as a women's issue rather than a human issue is erroneous". They propose that we should look beyond the traditional ways of investigating marital violence and try to understand and explain the problem keeping in mind that the victim and perpetrator roles can be played by both men and women.

One of the first researchers to identify marital violence against men found an equal amount of violent acts on the part of both partners (Gelles, 1974). Later, Gelles and Straus (1988) conducted a comparative study of the National Family Violence Surveys of 1975 and 1985. In their widely read paper, they stated that $11.6 \%$ of husbands reported experiencing abuse from their wives within the previous year and $4.6 \%$ reported being victims of severe violence (use of a knife or gun, kicking, beating, punching, etc.). The same author carried a more recent research (Strauss, 2001) where he studied prevalence of marital violence among students of 31 Universities worldwide. He reported that males and females had very similar rates of physical assaults toward their partners, even for severe assaults $(25 \%$ of men and $28 \%$ of women for physical assaults, and $9 \%$ for severe assaults for both genders). In a study of twenty-three dating couples, Archer and Ray (1989) found that women were more likely than men to use physical violence towards their partner. In an investigation conducted in New Zealand by Magdol, Moffit, Fagan, Newman and Silva (1997), 37.2\% of women and $21.8 \%$ of men reported being victims of physical violence in the previous year, whereas $18.6 \%$ of women and $5.7 \%$ of men reported being victims of severe violence. Other studies have made similar findings and established similar patterns of spou- 
sal abuse from both genders (Cascardi, Langhinrichsen, \& Vivian, 1992; Mason \& Blankenship, 1987; Margolin, 1987). Deal and Wampler (1986) found that $47 \%$ of their university student based sample had been victims of intimate violence. Most of the abuse was reported to be reciprocal and when it was not, men were three times more likely to report being the victims. Fiebert and Gonzalez (1997) studied a sample of college women in the United States to better understand women who initiate assault of their male partner. Twenty-nine percent of the women indicated they had initiated marital violence in the past five years; the two main motives were (a) because they did not think that their spouse would retaliate or would be injured and (b) as an attempt to draw emotional attention from them. Lafontaine and Lussier (2002) support this bidirectional model of intimate violence. They reported that both men and women were victims of physical and psychological violence.

Archer (2000) conducted a meta-analytic study on gender differences in marital aggression and found that even if women were more likely than their male partners to use physical aggression, they were also more likely to sustain injuries resulting from their partner's violence. This would suggest that although women may be physically abusing their partners, the latter's physical abuse is more likely to injure them. If the impact of violence is different between genders, it would also be possible that the perception and interpretation of the abuse from the other spouse would be different between males and females. According to a study conducted in 1991 by Follingstad, Wright and Sebastian, men interpret their partner's use of violence as a means of showing their anger or retaliation for feeling emotionally hurt or mistreated, while women describe their partner's intentions as a desire to gain control over them or as a retaliation for being assaulted first. In a study of college couples, Matthews (1984) found that both men and women, whether they were perpetrators or victims, would often interpret marital violent acts as a form of love. Holtzworth-Munroe and Hutchinson (1993) found that violent husbands are more likely to attribute blame, negative intents and selfish motivations to their wives. O'Leary and Vivian (1990) hypothesized that attributions can mediate aggressive behavior towards a spouse.

Previous studies have focused on attributions and variables underlying male and female marital violence. To our knowledge, no authors have studied the impact of perception of spousal violence on marital violence in a bi-directional model. An examination of both partners' perception of their mate's violence and of how it is linked to both partners' marital violence would be both innovative and fit nicely with previous studies of attributions as predictors of violence within the marriage. Somme issues in that matter would be interesting to explore. For instance, would self-reports and partner reports of violence be significantly different? Does one partner's abuse influence the other partner's level of physical and psychological violence and sexual coercion? If so, is it the one partner's actual violence or the other partner's perception of that violence that modulates the level of male and female marital violence? The present study addresses these questions and seeks to determine if there is a link between both spouses' perception of the other spouse's violence on one hand, and their levels of marital violence on the other hand. More precisely this study will try to better understand the relationship between the perception of the other spouse's violence on one hand and levels of marital violence on the other hand. It would also be of interest to know if attributions (Bradbury \& Ficham, 1990; Ficham, 1994) or the judg- ment on the part of one partner as to why the other partner resorts to violence in their exchanges, would differ for men and women.

\section{Objectives}

Our objectives were to verify the links between levels of violence and perceptions of violence by both partners, and actual self-reports of each type of violence perpetrated. More specifically, our objectives were to test 1) if self-reports and partner's reports of violence would differ significantly, 2) if one partner's abuses would influence the other partner's abuses, and 3) whether the spouse's self-reported violence or the other spouse's perception of that violence had a differential impact on the level of violence perpetrated.

\section{Method}

\section{Participants}

Our sample consisted of twenty-three couples where the male partner was undergoing treatment for physical domestic violence. The mean level of education for the women and men was 11.6 years and 11.3 years, respectively, ranging from less than a high school diploma (high school diploma $=11$ years) to a university degree (16 years). The mean age for the women and men was 30.3 years and 34 years, respectively. All the couples had children, with an average of 1.9 children per couple. In terms of annual income, $57.1 \%$ of the women earned $\$ 14,999$ or less, $19.1 \%$ earned between $\$ 15,000$ and $\$ 29,999,19.1 \%$ earned between $\$ 30,000$ and $\$ 44,999$, none of the women earned between $\$ 45,000$ and $\$ 59,999$, and $4.7 \%$ earned between $\$ 60,000$ and $\$ 74,999$. As for their male partners, $19 \%$ earned $\$ 14,999$ or less, $19 \%$ earned between $\$ 15,000$ and $\$ 29,999$, $23.8 \%$ earned between $\$ 30,000$ and $\$ 44,999,28.6 \%$ earned between $\$ 45,000$ and $\$ 59,999$ and $9.5 \%$ earned between $\$ 60,000$ and $\$ 74,999$. The couples were not necessarily living together at the time the male partner was receiving treatment. Fifteen percent of the couples had limited contact, $5 \%$ saw each other once a week, $15 \%$ saw each other several times a week, and $65 \%$ were still in a full-time relationship.

\section{Procedure}

The couples in the sample were recruited at a community center that offered treatment for violent men in the Montreal region (Canada). Both partners completed questionnaires that included both self- and partner reports of violence. Spouses were instructed not to discuss their answers with the other partner.

The intervention consisted of two pre-therapy meetings and 25 weekly group therapy sessions. Therapists presented the study to the men at the first meeting and if they agreed to participate they filled out the questionnaires after the second pretherapy meeting. Men were informed that their decision to participate in the study would not influence their therapeutic process in any way and that they were free to withdraw from the research project at any time. Questionnaires with a preaddressed envelope were also mailed to their partners. To ensure confidentiality and to prevent the men from exerting any kind of pressure on their partners, we informed the female partners that they were free to participate or not in our study and that their 
decision would not be divulged to their partner nor would it affect the therapy that their partner was undergoing.

\section{Instruments}

A French version of the Revised Conflict Tactics Scales (CTS2) originally developed by Straus et al. (1996) and translated and validated by Lussier (1997) was used to evaluate four different types of violent behavior: psychological violence, physical violence, sexual coercion, and injuries resulting from violence. In each couple, both spouses completed independently a questionnaire that included a self-report of their own violence and their perception of their spouse's violence for the four forms of violence examined. All items were rated according to the frequency of each violent behavior with eight different categories. Scores were calculated as follows: Except for scores of 0,1 or 2 (for which the score is the same as the middle point), it is obtained by addition of middle-points. When the participant answered 3 ( 3 to 5 times), the middle point was 4 , when they answered 4 ( 6 to 10 times), the middle point was 8 , for the answer 5 (11 to 20 times), the middle point was 15 and finally, for the category 6 (more than 20 times) the authors recommended to use 25 as the middle point. For the French version, alpha coefficients are acceptable and range from .70 to .79, except for physical violence, which has an alpha of .46. Alpha coefficients for the English version range from .79 to .95 , with psychological violence having the lowest score.

\section{Results}

Means and standard deviations for the violence subscales for men and women are presented on Table 1.

Correlational analyses were conducted between the women's different types of violence and their perception of their spouse's violence. Results: see Table 2.

Women's use of psychological violence appears to be linked to their perception of their spouse's psychological violence. As for women's physical violence, it is linked to their perception of their spouse's psychological and physical violence and use of sexual coercion, and their perception of the number of injuries they had sustained as a result of spousal abuse. The number of injuries that women inflicted on their husbands was linked to their perception of their spouse's physical violence and their perception of the number of physical wounds they had received as a result of spousal abuse.

We conducted correlational analyses between men's different types of violence and their perception of their partner's violence. Results are presented in Table 3.

It would appear that the only link between men's violence and their perception of their spouse's violence is the number of physical wounds inflicted on their spouse, which is in turn positively related to the number of wounds inflicted on them by the women.

Correlational analyses were conducted between women's self-report of violence and men's reports of their partner's violence. Results are presented in Table 4. Results indicate that the only form of men's violence as reported by both partners that seems to be correlated are the injuries inflicted to women by men.

We finally conducted correlational analyses between men's self-reports of violence and women's reports of their spouse's violence. Results are presented in Table 5.
Table 1.

Means and standard deviations on the different subscales of violence for men and women.

\begin{tabular}{|c|c|c|c|c|}
\hline & Psy. viol & Phys. viol & Coercion & $\begin{array}{l}\text { Injuries } \\
\text { inflicted }\end{array}$ \\
\hline خ's self-reports & $6.05(4.4)$ & $1.15(2.2)$ & $34(.7)$ & $57(1.2)$ \\
\hline $\begin{array}{c}\text { क's reports of } \\
\text { ठ's viol }\end{array}$ & $8.21(6.2)$ & $2.20(3.8)$ & $1.84(2.8)$ & $.99(2.1)$ \\
\hline O's self-reports & $3.61(3.8)$ & $.69(1.3)$ & $.025(.09)$ & $.18(.4)$ \\
\hline $\begin{array}{l}\text { ð’'s reports of } \\
\text { क's viol }\end{array}$ & $3.63(3.3)$ & $.71(1.1)$ & $18(.5)$ & $.33(.9)$ \\
\hline
\end{tabular}

Note: Psych. viol = psychological violence; Phys. viol = men's physical violence; Coercion = men's use of sexual coercion; Injuries inflicted $=$ Injuries inflicted on their spouse.

\section{Table 2.}

Links between women's violence and their perceptions of their spouse's violence.

\begin{tabular}{|c|c|c|c|c|}
\hline & $\begin{array}{l}\text { Psych. } \\
\text { viol. } \lambda\end{array}$ & Phys. viol. ${ }^{\lambda}$ & Coercion $\widehat{\partial}$ & $\begin{array}{c}\text { Injuries } \\
\text { inflicted }{ }^{\lambda}\end{array}$ \\
\hline Psych. viol. 우 & $.63, p=.002$ & & & \\
\hline Phys. viol. 우 & $.56, p=.007$ & $.82, p=.000$ & $.45, p=.035$ & $.75, p=.000$ \\
\hline $\begin{array}{l}\text { Injuries } \\
\text { inflicted } P\end{array}$ & & $.45, p=.03$ & & $.75, p=.000$ \\
\hline
\end{tabular}

Note: Psych. viol. $q$ = women's psychological violence; Phys. viol. $q$ = women's physical violence; Injuries inflicted $Q=$ Injuries inflicted by the women on their spouse; Psych. viol $\hat{\sigma}=$ men's psychological violence (as reported by women); Phys. viol $\hat{\sigma}=$ men's physical violence (as reported by women); Coercion $\hat{\sigma}=$ men's use of sexual coercion (as reported by women); Injuries inflicted $\hat{\sigma}=$ Injuries inflicted by the men on their spouse (as reported by women).

\section{Table 3.}

Correlations between men's violence and their perceptions of their spouse's violence.

\begin{tabular}{ll}
\hline & Injuries $\phi$ \\
\hline Injuries $\hat{\sigma}$ & $.631 \mathrm{p}=.001$ \\
\hline
\end{tabular}

Note: Injuries $\hat{\partial}=$ Injuries inflicted by men on their spouse; Injuries $q=$ Injuries inflicted by women on their spouse (as reported by the men).

Table 4.

Correlations between men's self-reported violence and men's violence as reported by their spouse.

\begin{tabular}{cc}
\hline & Injuries inflicted by $\widehat{\sigma}$ \\
\hline Injuries inflicted by $\widehat{\partial}($ ( $)$ & $.425 p=.043$ \\
\hline
\end{tabular}

Note: Injuries inflicted by $\hat{\sigma}=$ injuries inflicted by the men on their spouse; Injuries inflicted by $\hat{\partial}(\uparrow)=$ injuries inflicted by the men on their spouse (as reported by women).

Men and women seem to agree to a greater degree on their reports of different forms of women's violence. Their reports of women's use of psychological and physical violence and of sexual coercion seem to be correlated.

Paired sample t-tests were then carried out to detect any statistically significant differences between the men's and women's reports of violence. To accomplish this, we compared the women's self-reports of violence to women's violence as reported by the men. We then compared the men's self-reports of vio- 
Table 5.

Correlations between women's self-reported violence and women's violence as reported by their spouse.

\begin{tabular}{|c|c|c|c|}
\hline & Psych. viol. 우 & Phys. viol. + + & Sex. coercion + \\
\hline Psych. viol. $q\left({ }^{\lambda}\right)$ & $586 p=.003$ & & \\
\hline Phys. viol. $+\left(^{\Uparrow}\right)$ & & $.474 p=.022$ & \\
\hline Sex. coercion ㅇ $(\precsim)$ & & & $.586 p=.003$ \\
\hline
\end{tabular}

Note: Psych. viol. $ᄋ=$ psychological violence perpetrated by women (self-reports); Psych viol. $\bigcirc(ठ)=$ psychological violence perpetrated by women (as reported by men); Phys. viol. $O=$ physical violence perpetrated by women (selfreports); Phys. viol. $+\left(\partial^{\lambda}\right)=$ physical violence perpetrated by women (as reported by men); Sex. coercion $+=$ Sexual coercion used by women (self-reports); Sex. coercion $+(\widehat{)})=$ Sexual coercion used by women (as reported by men).

lence to the men's violence as reported by the women. Results showed that for women's psychological violence, physical violence and sexual coercion, the women's self-report numbers were higher than the men's report of the women's violence. However, the mean differences were not statistically significant. As for reports of injuries inflicted by the men, the men's self reports tended to be significantly higher than the women's reports of the men's violence.

\section{Discussion}

This study aimed at a better understanding of the role of perceptions of partner's violence as a regulator of both men and women's intimate violence. Results in regard to the differences in self-reports and partner's reports of violence, as well as the impact of perceptions on both partners' violence will be discussed.

Our results show that there is often a relationship between men's and women's reports of their spouse's violence and selfreports of their own violence. Although there were no statistically significant differences, men tended to under-report their partner's violence. This observation would detail with a report from O'Keefe (1997) who postulated that men may be reluctant to report violence perpetrated by their mate because they fear they would get a negative reaction from their peers.

In the present study, a significant difference was found between men's and women's reports of their partner's violence was with respect to injuries: compared to men's self-reports of injuries inflicted on their spouses, women tended to under-report the number of injuries received in the past year. Women may tend to underestimate the number of injuries they have received from their partners. This could possibly be interpreted by the fact that, if these women are still with their partners, they need to diminish their cognitive dissonance related to the fact that they are in a relationship with someone who hurts them.

As for the impact of perceptions on the various forms of violence perpetrated by women, their perception of their partner's violence was linked to their own violent behaviors. As women's perception of the level of their spouse's psychological abuse increased, their own psychological abuse increased. As their perception of their husband's psychological violence, physical violence, use of sexual coercion, and infliction of injuries increased, there was an increase in their own physical violence. Lastly, as women's perception of their spouse's physical violence and infliction of injuries increased, the level of injuries that they inflicted on their husbands increased.
For men, the only perception that appeared to be related to their violence was that the number of injuries they inflicted increased as the number of injuries they reported their spouse had inflicted on them in the past year increased.

It would thus appear that women's perceptions of their partner's violence provided a better explanation of their own violence than the actual levels of abuse perpetrated by their partner. This is an interesting finding because it portrays interpretations of marital violence as being different for men and women. Perceptions of spousal abuse may be an important component in our understanding of female violence. Interpreting female violence as self-defense (Pleck et al., 1978) does not appear to apply to the models of intimate violence proposed by most researchers, but it would be interesting to investigate further to learn why the notion of self-defense was thought to be the only reason underlying female violence. Verifying if abusive women perceived a threat prior to using violent behavior would give us an indication of why they plead self-defense, and if this is the case it would be interesting to work with them on perceptions of threat and actual signs of danger. It would appear that women who are in a relationship with a violent man report more violent acts by their spouse than the latter do. Perhaps, as O'Keefe (1997) indicated, men are hesitant to report being victimized in their close relationship because they are afraid of not being taken seriously. Also, it is important to differentiate the women of our sample from women in the general population who are in a violent relationship. It is possible that the women in our sample have already identified the fact that they are in a violent relationship and have hence taken action to deal with this problem. Their spouse being in treatment usually means either that they were arrested for marital violence, most often because the wife had called the police, or that they were "strongly" advised by their spouse to enter a treatment program. Our results need to take into account this idiosyncracy and thus cannot be generalized to all women in violent relationships.

Women also seem to perpetrate more violent acts when they perceive violence on the part of their partner. Are these women's perceptions altered by the fact that they are in a relationship with a violent man? Are women excusing their own violence by associating it with perceptions of their husband's violence? Why is perception of spousal abuse a more significant variable in explaining female violence than it is for men? Perhaps women are more inclined to listen to their feelings or emotions before acting out violence. Their feelings of fear may alter the perception they have of their spouse's violence and provide them with the incentive they need to defend themselves. Lafontaine and Lussier (2005) reported a link between insecure attachment and anger, and marital violence. There may be a relation between a woman's fear and type of attachment, and her level of violence towards her partner. Further studies need to explore these questions by examining the link between emotions and perpetration of violence in both men and women. Additionally, these studies could analyse the link between perceptions of the partner's violence and other marital variables such as marital adjustment and attachment and (Gosselin, Lafontaine, \& Bélanger, 2005).

\section{Limitations of the Present Study}

The present study has some limitations. First, since the number of couples $(n=23)$ is relatively small, it is possible that our sample is not representative of couples in the general popula- 
tion where the man is identified as being violent. The coup les in our study were recruited in a facility offering group counseling for violent men; perhaps not all violent men seeking help are interested in this form of therapy. Wealthier and more educated men may opt for private counseling or other forms of help they can afford. A second limitation is the fact that we relied on CTS2 reports and did not measure each partner's attributions of their spouse's violence. The CTS2 does not take into account the context in which the violence takes place. It is thus very difficult to determine which partner initiated the violence. Perhaps men or women in our sample under-reported levels of violence for social desirability reasons, which we did not measure. Further studies could investigate links between perceptions of spousal violence and violent acts with other measures that are specifically designed to interpret perceptions of intimate violence.

Differences between self-reported violence and violence as reported by the spouse for both partners were presented. Our findings provide a new look at the impact of perception of spousal violence on the level of marital violence of both spouses. Clearly, it would be beneficial for future research to investigate bi-directional marital violence in other populations such as couples seeking help for therapy, couples from the general population or couples in which the man has been violent but who is not interested in seeking help for his problem. This research could be replicated with the addition of a questionnaire which would permit to identify the instigator of violence. It would also be of interest to measure perceptions of violence. Further research should aim at differentiating women and men's intimate violence by adding interpretations of violent behaviors from the partner, in addition to his/her own perceptions of violence, as a complement to actual violent behaviors. This distinction could be crucial to increase efficacy in treating these individuals, because false perceptions and attributions are central in the communicational dysfunctions and emotional dysregulation that characterize these couples.

\section{Acknowledgements}

This publication was funded by a Canadian grant from the Social Sciences and Humanities Research Council (SSHRC) to the first author.

\section{REFERENCES}

Archer, J., \& Ray, N. (1989). Dating violence in the United Kingdom: A preliminary study. Aggressive Behavior, 15, 337-343. http://dx.doi.org/10.1002/1098-2337(1989)15:5<337::AID-AB24801 50502>3.0.CO;2-0

Archer, J. (2000). Sex differences in aggression between heterosexual partners: A meta-analytic review. Psychological Bulletin, 126, 651680. http://dx.doi.org/10.1037/0033-2909.126.5.651

Bradbury, T. N., \& Ficham, F. D. (1995). Attribution in marriage. Psychological Bulletin, 107, 3-33.

http://dx.doi.org/10.1037/0033-2909.107.1.3

Cascardi, M., Langhinrichsen, J., \& Vivian, D. (1992). Marital aggression; Impact, injury, and health correlates for husbands and wives. Archives of internal Medicine, 152, 1178-1184.

http://dx.doi.org/10.1001/archinte.1992.00400180048007

Deal, J. E., \& Wampler, K. S. (1986). Dating violence: The primacy of previous experience. Journal of Social and Personal Relationships, 3, 457-471. http://dx.doi.org/10.1177/0265407586034004

DeMaris, A. (1992). Male versus female initiation of aggression: The case of courtship violence. In E. C. Viano (Ed.), Intimate violence:
Interdisciplinary perspectives (pp. 111-120). Bristol, PA: Taylor \& Francis.

Ficham, F. D. (1994). Cognition in marriage. Applied and Preventive Psychology, 3, 185-198. http://dx.doi.org/10.1016/S0962-1849(05)80070-8

Fiebert, M. S., \& Gonzalez, D. M. (1997). Women who initiate assaults: The reasons offered for such behavior. Psychological Reports, 80, 583-590. http://dx.doi.org/10.2466/pr0.1997.80.2.583

Follingstad, D. R., Wright, S., \& Sebastian, J. A. (1990). Sex differences in motivations and effects in dating violence. Family Relations, 40, 51-57. http://dx.doi.org/10.2307/585658

Gelles, R. J. (1974). The violent home: A study of physical aggression between husbands and wives. Beverly Hills, CA: Sage Publications.

Gosselin, M., Lafontaine, M. F., \& Bélanger, C. (2005). L'impact de 1'attachement sur la violence conjugale: L'état de la question. Bulletin de Psychologie, 58, 579-588. http://dx.doi.org/10.3917/bupsy.479.0579

Lafontaine, M. F. (2002). Are typologies of psychological and physical couple violence linked to romantic attachment and dyadic adjustment? Unpublished Theses, Trois-Rivieres: University of Quebec.

Lafontaine, M. F., \& Lussier, Y. (2005). Does anger towards the partner mediate and moderate the link between romantic attachment and intimate violence. Journal of Family Violence, 20, 349-361. http://dx.doi.org/10.1007/s10896-005-7797-5

Lussier (1997). A French translation of the revised conflict tactics scales. Unpublished Manuscript, Trois-Rivieres: University of Quebec.

Mangdol, L., Moffitt, T. E., Fagan, J., Newman, D. L., \& Silva, P. A. (1997). Gender differences in partner violence in a birth cohort of 21 year olds: Bridging the gap between clinical and epidemiological approaches. Journal of Consulting and clinical Psychology, 65, 68-78. http://dx.doi.org/10.1037/0022-006X.65.1.68

Margolin, G. (1987). The multiple forms of aggressiveness between marital partners: How do we identify them? Journal of Marital and Family Therapy, 13, 77-84.

http://dx.doi.org/10.1111/j.1752-0606.1987.tb00684.x

Marshall, L. L., \& Rose, P. (1987). Premarital violence: The impact of the family of origin violence, stress and reciprocity. Violence and victims, 5, 51-64.

Mason, A., \& Blankenship, V. (1987). Power and affiliation motivation, stress and abuse in intimate relationships. Journal of Personality and Social Psychology, 52, 203-210. http://dx.doi.org/10.1037/0022-3514.52.1.203

Matthews, W. J. (1984). Violence in college couples. College Student Journal, 18, 150-158.

McNeely, R. L., \& Mann, C. R. (1990). Domestic violence is a human issue. Journal of Interpersonal Violence, 5, 129-132. http://dx.doi.org/10.1177/088626090005001012

McQueen, D. (2011). Violence is most commonly reciprocal. The Psychiatrist, $35,33$.

O'Keefe, M. (1997). Predictors of dating violence among high school students. Journal of Interpersonal Violence, 12, 546-568. http://dx.doi.org/10.1177/088626097012004005

Pleck, E., Pleck, J. H., Grossman, M., \& Bart, P. B. (1978). The battered data syndrome: A comment on Steinmetz's article. Victimology: An International Journal, 2, 680-683.

Straus, M. A., \& Gelles, R. J. (1986). Societal change and change in family violence from 1975 to 1985 as revealed by two national surveys. Journal of Marriage and the Family, 48, 465-479. http://dx.doi.org/10.2307/352033

Straus, M. A. (1995). Trends in cultural norms and rates of partner violence: An update to 1992. In S. M. Stitch, \& M. A. Straus (Eds.), Understanding partner violence: Prevalence, causes, consequences, and solutions (pp. 30-33).

Strauss, M. (2001). Prevalence of violence against dating partners by male and female university students worldwide. Violence against Women, 10, 790-811. http://dx.doi.org/10.1177/1077801204265552

Williams, J. R., Ghandour, R. M., \& Kub, J. E. (2008). Female perpetration of violence in heterosexual intimate relationships. Trauma Violence Abuse, 9, 227. http://dx.doi.org/10.1177/1524838008324418 


\section{BÉLANGER ET AL.}

Whitaker, D. J., Haileyesus, T., Swahn, M., \& Saltzman, L. S. (2007).

Differences in frequency of violence and reported injury between re-

lationships with reciprocal and nonreciprocal intimate partner vio- lence. American Journal Public Health, 97, 941-947.

http://dx.doi.org/10.2105/AJPH.2005.079020 